\title{
Measurement of Regional Agricultural Sustainable Development System Based on Dissipative Structure Theory: A Case Study in Sichuan Province, China
}

\author{
Fumin Deng, Canmian Liu and Xuedong Liang * \\ The Economy and Enterprise Development Institute, Sichuan University, Chengdu 610065, China;

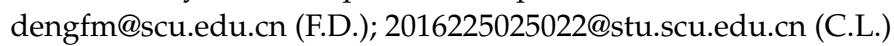 \\ * Correspondence: liangxuedong@scu.edu.cn; Tel.: +86-28-85415581
}

Received: 7 August 2017; Accepted: 6 November 2017; Published: 8 November 2017

\begin{abstract}
Aiming at the sustainable development issue of agriculture, the regional agricultural sustainable development system is regarded as a complex giant dissipative system in this paper by using the theory of dissipative structure. In order to effectively measure the coordinated development status and orderly evolution trend of the system, the more comprehensive and scientific index system was constructed from the framework of economy, society, technology, resource and environment (ESTRE). The measurement model of the system was constructed by using the method of information entropy, and an empirical analysis of Sichuan province from 2005 to 2015 was conducted. The results show that with the advancement of the years, the agricultural sustainable development system in Sichuan province is evolving in a more orderly and coordinated direction. The measurement results are in agreement with the actual situation and verify the effectiveness of the system measurement model in the regional agricultural sustainable development measure.
\end{abstract}

Keywords: dissipative structure theory; entropy; regional agricultural sustainable development system; Sichuan Province

\section{Introduction}

As the most basic industry relying on natural resources and ecological environment, agriculture plays an important role in promoting the national economy and people's life [1]. Sustainability in agriculture has become an important consideration for the Sustainable Development Goals (SDGs) [2]. The region is an area with cohesion and homogeneity, which can be demarcated by a single or a few characteristics [3]. Regional agriculture sustainable development is a production mode of agriculture, and it means that in a certain agricultural region, from the maintaining sustainability of economy, society and ecology, it can not only meet the demand of contemporary people with respect to agricultural products, but also it does no harm in meeting the needs of future generations. Since the 21st century, developed countries have taken the lead in applying modern technology and modern industrial technologies to agricultural development, such as the promotion and application of agricultural machinery, fertilizers, pesticide inputs and agricultural hybridization techniques, which have significantly increased labor productivity and land productivity [4]. However, the development of modern agriculture also has two sides; it has caused the imbalanced development of the natural population, ecological resources and social economy, affected the survival of contemporary people and the development of the continuation of future generations, and resulted in numerous inevitable disasters, such as drought, water and soil erosion, climate variation, resource depletion, etc. These current situations have urged the sustainable development of agriculture to become the focus of human society today. In order to promote the concept of agricultural sustainability systems, it is important to operationalize the assessment of sustainability, by evaluating the sustainability of existing 
practices and initiatives [5,6], exploring the evolutionary trend and impact mechanism of agricultural sustainable development systems, effectively measure the sustainable development of agriculture, and ensuring the coordinated and orderly operation of agricultural sustainable development systems. Therefore, in this paper, the complex evolution of a regional agriculture sustainable development system is analyzed by using the theory of dissipative structure; the index system is constructed according to the influential factors of entropy increase and entropy decrease, and the measurement model of the system is built using the information entropy method; subsequently, the empirical study of Sichuan province is conducted. The research framework is shown in Figure 1.

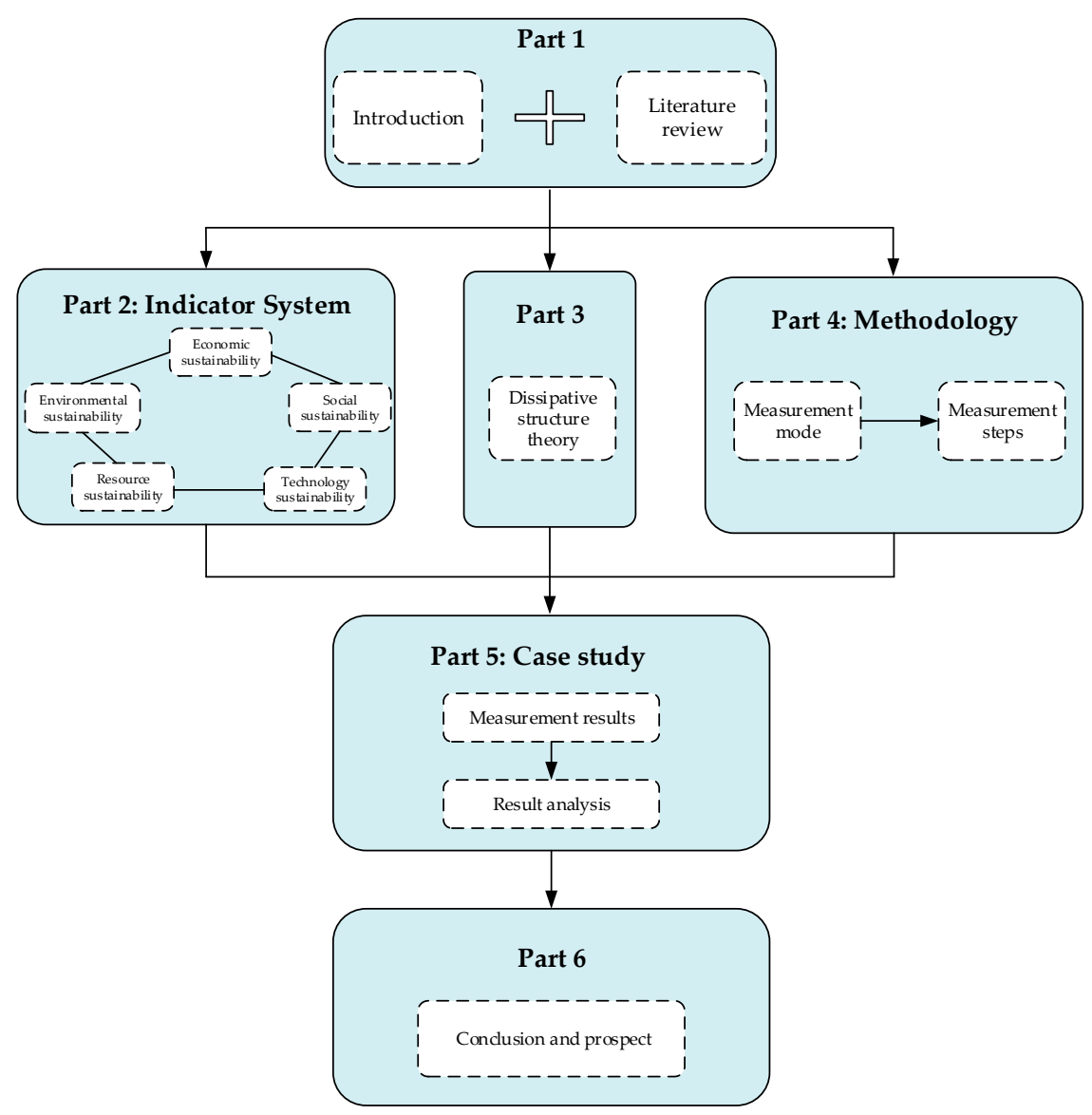

Figure 1. Research framework of regional agricultural sustainable development.

\section{Literature Review}

\subsection{Research on The Measurement of Regional Agricultural Sustainable Development}

Until now, research on the measurement of regional agricultural sustainable development has focused mainly on the construction of a measure index system and the choice of measure method.

(1) From the construction of a regional agricultural sustainable development measure index, because of the research focus and the difference in agricultural regional development, the measure indexes selected by scholars at home and abroad are different. Yuan [7] constructed a hierarchical structure model for evaluating the level of agricultural sustainable development from 5 aspects of population, economy, society, resources and environment, which comprehensively reflected the content of agricultural sustainable development. Cao [8] constructed an agricultural sustainable development index system from four aspects of economy, production factors, society, resources and environment, and focused on analyzing the sustainable development of agriculture from 
the angle of economic output efficiency and social development benefit. Gomez-Limon [9] considered sustainable agriculture as an activity that needs to be sustained from the three dimensions of economics (operating profitability), social justice (fair and equitable distribution of wealth) and environment friendly (compatible with conservation of natural ecosystems). Baumgartner [10] and Rasul [11] argued that the sustainable development of agriculture should fully take into account the three dimensions of ecology, economy and society, and that ecological sustainability is the most important among them. Gustavson [12], based on the PSR framework (Press-State-Response), selected 23 indicators for watershed sustainability assessment, which focused on the sustainability of the natural ecology of the basin. The European Community monitored the status of agriculture with five indicators of per capita cultivated land, land-use change, agricultural energy, fertilizers and pesticides recommended by the United Nations Commission on Sustainable Development (UNCSD), which can better reveal the capacity of agricultural sustainable development [13].

(2) From the perspective of regional agricultural sustainable development measures, there are more than 100 evaluation tools in the world due to the impact of the sustainable development assessment framework on local agricultural priorities and practices [14]. However, the academic circles mainly adopted the methods of comprehensive index evaluation, multivariate statistical analysis and so on. System dynamics [15], Emergy analysis [16,17], Grey relational analysis [18], and so on are applied to the sustainable development of agricultural systems. Cahya [19] quantitatively analyzed the characteristics of Metropolitan Jakarta's sustainable development of urban agriculture through multidimensional scale (MDS) methods. Dong [20] combined non-negative principal component analysis (PCA) and data envelopment analysis (DEA) to assess the performance of individual farms in agricultural sustainability. In addition, Lu [21] adopted the osculating value method (a multi-objective decision optimization method) to construct a comprehensive model of rural sustainable development in China, quantified the model indicators, and conducted comprehensive comparison of the sustainable development level of rural areas in China. Vlontzos [22] adopted the non-radial data envelopment analysis (DEA) model to estimate the agricultural energy and environmental efficiency of EU member States.

\subsection{Summary of Previous Research}

In the research system of the agricultural sustainable development, we found some deficiencies.

In research on the whole system of sustainable development, most scholars focus on the economic and ecological aspects, such as research on the sustainable development between the agricultural ecological environment and agricultural economy, ignoring the sustainability of social, technology, resources and other factors. However, the core of sustainability is that human social and economic development cannot exceed the carrying capacity of technological development and the resource environment. A sustainable development system of regional agriculture needs to cover related content of economic, resource and environment and also meet the demands of social stability and technological development. Therefore, in the measurement of an agricultural sustainable development system, we need to consider the factors of economy, society, technology, resources and environment, determine the interaction and influence of each factor, and comprehensively and accurately reflect the sustainable development of regional agriculture. In the construction and evaluation of indicators, some scholars use qualitative analysis and subjective evaluation (such as analytic hierarchy process), which have strong subjectivity, and to some extent influence the scientific rigor of the study results. In the study of sustainable development of regional agriculture, most scholars focus on the macro level, and there is little research on the internal mechanism and evolutionary trend of sustainable development systems.

In order to overcome the limitations of previous research, first of all, the objective evaluation method-information entropy method-will be used to weight the measure indexes of regional agriculture sustainable development from objective and scientific perspectives. Secondly, in addition to the exploration of the evolution law of a regional agricultural sustainable development system based 
on the dissipative structure theory, the coordinated development of the micro structure function of the system is also deeply analyzed in this paper. Dissipative structure theory belongs to the theoretical level of system science [23], revealing the conditions and mechanism of a system from disorder to order; improving system science to the stage of the research system and evolution has been widely used in the evolution of land structure [24], water resource systems [25], urban resource systems [26], the human-earth system [27] and so on. Therefore, in this paper, the theoretical method of dissipative structure and the evaluation mechanism of information entropy are used to quantitatively analyze and measure the sustainable development of regional agriculture.

Based on the dissipative structure theory and information entropy method, the measurement model of a regional agricultural sustainable development system is constructed, and the sustainable development of agriculture in Sichuan province is analyzed, which can provide a reference for the relevant research of regional agriculture sustainable development. Accordingly, the innovations of this paper are presented from the following three aspects.

(1) Effective measurement of regional agricultural sustainable development from the perspective of system theory. The complex giant system of regional agriculture sustainable development is divided into five subsystems of economy, society, technology, resource and environment. Combined with the actual development of regional agriculture, the measurement index is constructed under each subsystem, and then according to the standardization value and weight of each measure index, the sustainable development level score of each subsystem and the comprehensive score value of the total system sustainable development are obtained.

(2) The dissipative structure theory and entropy theory are applied to the analysis and research of the regional agricultural sustainable development system. According to the influential factors of system entropy increase and entropy decrease, the index system is constructed, and the mechanism of the system is analyzed, and the structural characteristics and order degree of the evolution process of the regional agricultural sustainable development system are characterized by the change in the entropy value.

(3) Based on the calculation of yearly information entropy, a comprehensive development score and coordination degree, the coordinated development status and orderly evolution trend of regional agricultural sustainable development system in different years are analyzed from the perspective of time series.

\section{Dissipative Structure of Regional Agricultural Sustainable Development System}

Dissipative structure theory is proposed by Prigogine; its core idea is that when the external conditions change to a certain threshold, an open system away from the equilibrium state can change from the original disordered state to a new state of time, space or function through the exchange of material and energy with the outside world. An agricultural sustainable development system is an open composite system combined by economic, social, technology, resource and environmental factors; its mechanism is shown in Figure 2. In the process of its evolution, the following dissipative structural features are available, so the complex evolution of agricultural sustainable development system can be well analyzed by dissipative structure theory. 


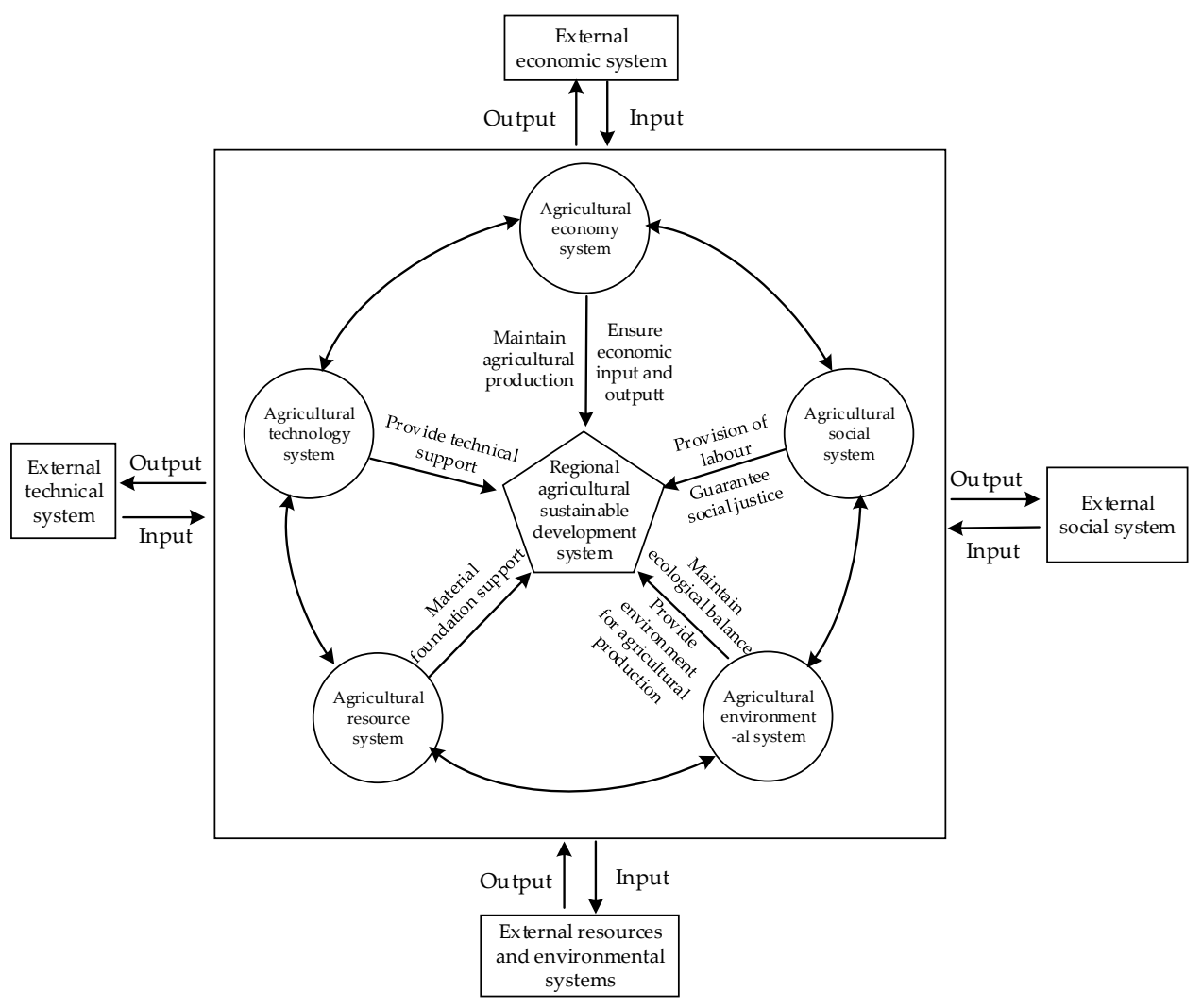

Figure 2. Dissipative structure of regional agricultural sustainable development system.

\subsection{Open System}

The regional agricultural sustainable development system consists of economy, society, technology, resources and environmental factors in a complex-giant system rather than an isolated system. The system has dynamic internal structure, the subsystems are interdependent and mutually restrictive, and there is mutual transfer and conversion of logistics, energy flow, information flow and technology flow. On the one hand, the agricultural economic development and the material production materials required by farmers are directly and indirectly obtained from the agricultural environment and resources subsystem. On the other hand, the various theories, ideas, technology and management models produced by the economic, social and technological systems also directly or indirectly affect the state of the agricultural environment and resource subsystem. Thus, the regional agricultural sustainable development system is a dynamic-open system with the exchange of material, energy, information and technology.

\subsection{Stay Away from Equilibrium}

The regional agricultural sustainable development system consists of multiple subsystems, each of which has its own characteristics in terms of function and mechanism. In equilibrium and near equilibrium states, the material and energy distribution of each subsystem in the system are completely uniform, there is no potential energy difference, and the interference factors are always damped by the stability of the system itself; the system eventually tends to be a completely disordered status of chaos. In fact, the regional agricultural sustainable development system is in constant interaction with the external system, and the exchange of material and energy between the various links on the outside and the system constantly urges the system to keep away from equilibrium, to maintain a non-equilibrium dynamic, and then produce a new ordered structure. 


\subsection{Nonlinear Dynamic Mechanism}

When the regional agricultural sustainable development system is far from equilibrium to a certain point under the external conditions, the function of each subsystem of the system is normal. When the total function of the system is larger than the function of each subsystem, the regional agricultural sustainable development system begins to move into the non-equilibrium nonlinear region, producing a dynamic characteristic - the nonlinear organization mechanism, and then forms an orderly and functional self-organization structure, that is, the stable and orderly dissipative structure.

\section{Construction and Analysis of Positive and Negative Entropy Flow Indicator System}

In the theory of dissipative structure, the process of entropy increase is a spontaneous process from orderly to disorder [28]. The factors that lead to the entropy increase of a regional agricultural sustainable development system are population factors, resource depletion, ecological destruction and so on. Negative entropy flow can reduce the total entropy of the system to avoid the equilibrium state, to maintain a non-equilibrium state, and then to produce a new ordered structure. The main entropy reduction factors include the support of property, technology innovation, ecological restoration and the improvement of compensation mechanisms [25]. Seeking the entropy increase and entropy reduction factor of sustainable development of a regional agricultural system can help to clarify the negative impact of sustainable development of the agricultural system and introduce negative entropy flow to promote the coordinated and orderly development of the system. In the construction of the indicators of regional agricultural sustainable development, it is necessary to take into account the rationality of the evaluation indicators, but also to ensure that the evaluation indicators can truly reflect the status of regional agricultural sustainable development, and for a considerable period of time with sufficient comparability and applicability. Therefore, under the principle of systematic, scientific, representative, accessibility and operability index system construction, based on the existing research results, combined with the actual situation of agricultural sustainable development in Sichuan province, according to the influential factors of system entropy increase and entropy reduction, the regional agricultural sustainable development system measurement index system is constructed from the five dimensions of economy, society, technology, resources and environment (Framework of ESTRE), as shown in Table 1.

Table 1. Index system based on the ESTRE framework.

\begin{tabular}{|c|c|c|c|c|}
\hline Object Layer & Rule Layer & Indicator Layer & $\begin{array}{l}\text { Indicator } \\
\text { Attribute }\end{array}$ & $\begin{array}{l}\text { Data } \\
\text { Source }\end{array}$ \\
\hline \multirow{6}{*}{$\begin{array}{l}\text { Regional Agricultural } \\
\text { Sustainable } \\
\text { Development System }\end{array}$} & \multirow{4}{*}{$\begin{array}{c}\text { Economic } \\
\text { subsystem (E) }\end{array}$} & $\begin{array}{l}\text { Gross agricultural product per capita } \\
\text { (yuan/person) C11 }\end{array}$ & Entropy reduction & [29] \\
\hline & & $\begin{array}{l}\text { Per capita net income of rural households } \\
\text { (yuan/person) } \mathrm{C} 12\end{array}$ & Entropy reduction & [29] \\
\hline & & Land productivity $\left(\mathrm{kg} / \mathrm{hm}^{2}\right) \mathrm{C} 13$ & Entropy reduction & [29] \\
\hline & & Per capita grain production (kg/person) C15 & Entropy reduction & [29] \\
\hline & \multirow{2}{*}{$\begin{array}{c}\text { Social } \\
\text { subsystem (s) }\end{array}$} & Regional population density (person $/ \mathrm{km}^{2}$ ) C21 & Entropy increase & [29] \\
\hline & & Natural population growth rate (\%) C22 & Entropy increase & [29] \\
\hline
\end{tabular}


Table 1. Cont.

\begin{tabular}{|c|c|c|c|c|}
\hline Object Layer & Rule Layer & Indicator Layer & $\begin{array}{l}\text { Indicator } \\
\text { Attribute }\end{array}$ & $\begin{array}{l}\text { Data } \\
\text { Source }\end{array}$ \\
\hline \multirow{15}{*}{$\begin{array}{l}\text { Regional Agricultural } \\
\text { Sustainable } \\
\text { Development System }\end{array}$} & \multirow{5}{*}{$\begin{array}{c}\text { Technical } \\
\text { subsystem }(\mathrm{T})\end{array}$} & $\begin{array}{l}\text { Number of agricultural scientific research projects } \\
\text { (items) C } 31\end{array}$ & Entropy reduction & [30] \\
\hline & & $\begin{array}{l}\text { Input personnel of agricultural scientific research } \\
\text { (persons) C32 }\end{array}$ & Entropy reduction & [30] \\
\hline & & $\begin{array}{l}\text { Investment in agricultural scientific research } \\
(10,000 \text { yuan }) \text { C } 33\end{array}$ & Entropy reduction & [30] \\
\hline & & Number of agricultural patent applications (items) C34 & Entropy reduction & [30] \\
\hline & & Technical market contract amount (10,000 yuan) C35 & Entropy reduction & [30] \\
\hline & \multirow{5}{*}{$\begin{array}{c}\text { Resource } \\
\text { subsystem (R) }\end{array}$} & Per capita cultivated land ( $\mathrm{hm}^{2} /$ person) $\mathrm{C} 41$ & Entropy reduction & [29] \\
\hline & & Per capita water resources ( $\mathrm{m}^{3} /$ person) $\mathrm{C} 42$ & Entropy reduction & [31] \\
\hline & & Effective irrigation area $\left(10,000 \mathrm{hm}^{2}\right) \mathrm{C} 43$ & Entropy reduction & [29] \\
\hline & & $\begin{array}{l}\text { Total mechanical power of unit cultivated land } \\
\left(\mathrm{kW} / \mathrm{hm}^{2}\right) \mathrm{C} 44\end{array}$ & Entropy reduction & [29] \\
\hline & & $\begin{array}{l}\text { Per capita electricity consumption in rural } \\
(\mathrm{kw} \mathrm{h} / \text { person) } \mathrm{C} 45\end{array}$ & Entropy reduction & [29] \\
\hline & \multirow{5}{*}{$\begin{array}{l}\text { Environment } \\
\text { subsystem (E) }\end{array}$} & Intensity of pesticide use $\left(\mathrm{kg} / \mathrm{hm}^{2}\right) \mathrm{C} 51$ & Entropy increase & {$[31]$} \\
\hline & & Intensity of Agricultural fertilizer use $\left(\mathrm{kg} / \mathrm{hm}^{2}\right) \mathrm{C} 52$ & Entropy increase & {$[31]$} \\
\hline & & Intensity of plastic use $\left(\mathrm{kg} / \mathrm{hm}^{2}\right) \mathrm{C} 53$ & Entropy increase & {$[31]$} \\
\hline & & Disaster area of agriculture $\left(10,000 \mathrm{hm}^{2}\right) \mathrm{C} 54$ & Entropy increase & [29] \\
\hline & & Governance area of soil erosion $\left(1000 \mathrm{hm}^{2}\right) \mathrm{C} 55$ & Entropy reduction & [31] \\
\hline
\end{tabular}

In this indicator system, the regional agricultural sustainable development system is divided into five criteria layers of economic subsystem, social subsystem, technical subsystem, resource subsystem and environment subsystem. Based on each criterion layer, the indicators are constructed, and the selected logic is as follows:

Economic sustainability is reflected not only in the current economic growth but also in the sustainable improvement of agricultural production and the economy in the future [32]. The economic subsystem covers all kinds of economic factors resulting from the sustainable development of regional agriculture, which includes all economic strategies, economic behavior and economic capacity [20]. Its function is to optimize the agricultural economic structure and increase the level of agricultural production on the basis of ensuring the carrying capacity of natural resources and ecological environment. The economic subsystem is the core of sustainable development of regional agriculture, which enables the region to maintain a higher level of input and output for a longer period of time and to ensure the sustainable output of food. The economic indicators selected in this paper, such as gross agricultural product per capita, investment in fixed assets of agriculture, per capita net income of rural households and so on, reflect the transformation structure between input and output of regional agricultural economic production factors.

The sustainability of the society is that the income of the peasants can meet the needs of their living beings and promote the long-term and stable development of the agricultural industry by expanding the comprehensive quality of the laborers and making the distribution of social resources more equitable [33]. The sustainable development of the social subsystem can ensure the healthy development of the social environment needed for the sustainable development of agriculture, and reflect the ultimate goal of the sustainable development of agriculture: to improve people's living standard and establish a harmonious and stable social situation. Indicators that affect the sustainable development of society, such as the regional population density, the natural population growth rate and the proportion of the rural education population, reflect the rural population size and the quality of the labor force. The rural residents Engel coefficient and urbanization rate reflect the farmers' living conditions. 
The technology subsystem includes technological innovation, technology promotion and application within agriculture or with other industries. It provides technical support for the development of agricultural economy and society and the rational utilization of natural environment resources. In the main indicators affecting the sustainable development of agricultural technology, the number of agricultural scientific research projects, input personnel of agricultural scientific research, and investment in agricultural scientific research, the number of agricultural patent applications reflect the situation of agricultural technology development and knowledge output to a certain extent, while the technical market contract amount reveals the economic benefits brought by the development of agricultural technology.

The sustainability of the ecology is manifested as follows: in the development of modern agriculture, we should maintain the renewable resources to protect their productive capacity, while economizing on non-renewable resources and preventing environmental pollution. The resource subsystem provides the material energy foundation for the development of a regional agricultural economic system; the excessive consumption of resources will cause a shortage of resources and environmental pollution, and restrict the development of the economy. Rural land resources, hydropower resources, agricultural machinery and other factors are the key to the sustainable development of resources.

The sustainability of environmental subsystems provides a good ecological environment for agricultural production and is the fundamental guarantee for the sustainable development of agriculture. While making rational use of natural resources, we should pay attention to the development of the ecological environment at all times. On the one hand, the amount of agricultural chemical fertilizer, plastic film and pesticide has a negative impact on the ecological environment, such as reducing the bearing capacity and production performance of the ecological environment. On the other hand, reducing the area of agricultural disasters and comprehensive treatment of soil erosion can improve the overall function of the ecological environment.

In addition, the system dissipative structure theory shows that the index of each subsystem is not limited to the internal reaction in its system but also plays an important role in every subsystem. There are positive effects (for example, an increase in rural education will increase input of personnel in agricultural scientific research) and negative feedback (for example, an increase in the per capita income of rural households will reduce Engel's coefficient of rural residents) between indicators, and the coordination and restriction between each other maintain the sustainable development system of agriculture in the whole region in the state of dynamic equilibrium, and the whole system shows the result of the interaction between the indexes, as shown in Figure 3. 


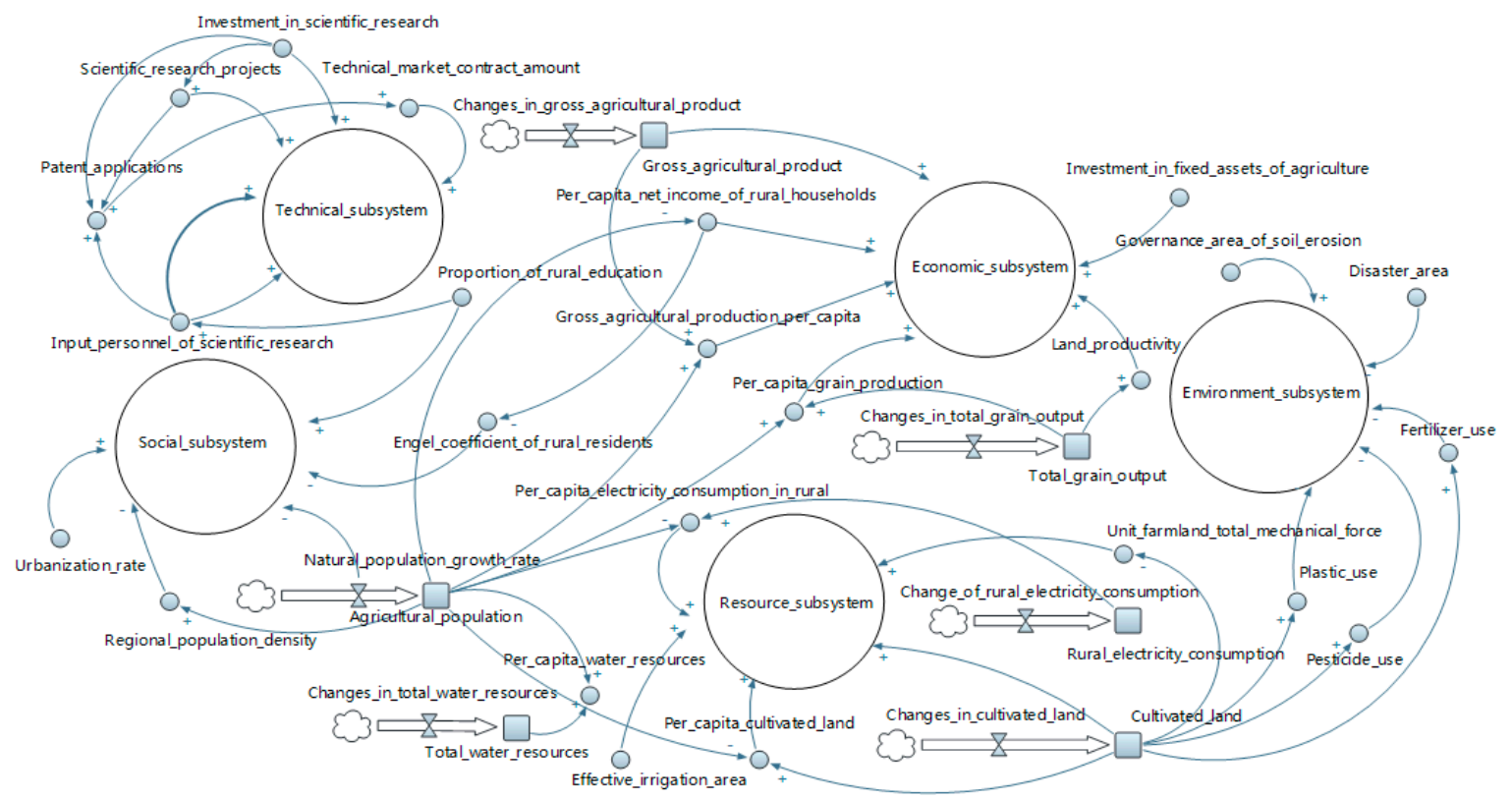

Figure 3. Model flow diagram of regional agricultural sustainable development system. Note: "+" indicates that there is a positive feedback between the indicators, " - " indicates that there is a negative feedback between the indicators.

\section{Measurement Method of Regional Agricultural Sustainable Development System}

\subsection{Measurement Mode}

In the dissipative structure theory, entropy is used to describe whether the evolution of the system is orderly. The change of entropy determines the evolution of the system. The total entropy of system $\left(\mathrm{dS}_{\text {total }}\right)$ is equal to the sum of "entropy generation" $\left(\mathrm{dS}_{1}\right)$ and "entropy flow" $\left(\mathrm{dS}_{2}\right)$, that is, $\mathrm{dS}_{\text {total }}=\mathrm{dS}_{1}+\mathrm{dS}_{2}$. A complex system can increase the negative entropy flow of the system by constantly exchanging itself with the external factors, so that the total entropy will decrease and the whole system will gradually develop in an orderly direction On the other hand, increasing the internal entropy of the system will increase the total entropy, and the whole system will develop in a chaotic and disorderly direction. Therefore, combined with the theory of dissipative structure, the concept of information entropy can be used to quantitatively analyze the situation of regional agricultural sustainable development system, and the information entropy method can be used to calculate the index information entropy and year information entropy of the system. Among them, the index information entropy is used to determine the weight of each index, and then the sustainable development score and coordination value of the system are calculated to characterize the coordinated development of regional agricultural sustainable development system. Annual entropy information is used to analyze the order and evolution trend of a regional agricultural sustainable development system. The measurement model is shown in Figure 4. 


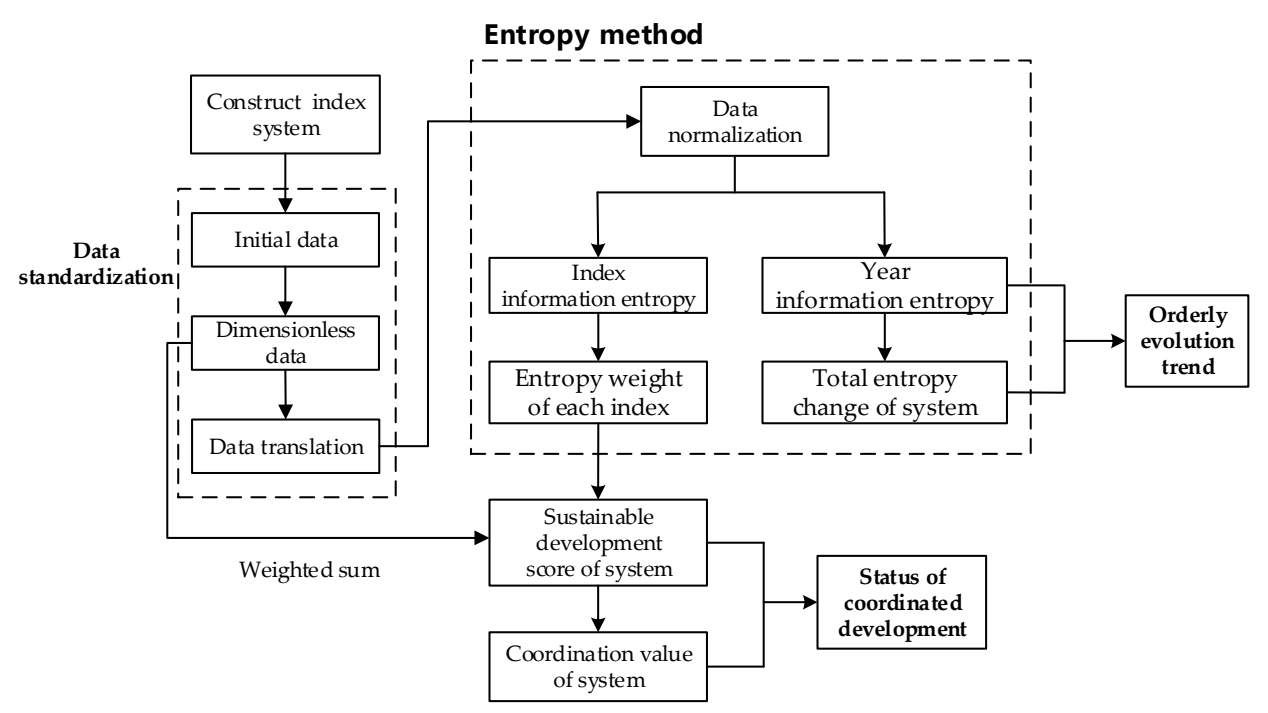

Figure 4. Measurement model of regional agricultural sustainable development system.

\subsection{Measurement Steps}

According to the measurement model of the regional agricultural sustainable development system above (Figure 4), the specific analytical steps are as follows:

\subsubsection{Standardization of Indicator Data}

In order to effectively implement the regional agricultural sustainable development measure, assume that there are $m$ years, $n$ measure indicators, and the initial measure matrix $X^{\prime}$ is constructed.

$$
X^{\prime}=\left[\begin{array}{cccc}
x_{11}{ }^{\prime} & x_{12}{ }^{\prime} & \ldots & x_{1 n^{\prime}} \\
x_{21}{ }^{\prime} & x_{22}{ }^{\prime} & \cdots & x_{2 n}{ }^{\prime} \\
\vdots & \vdots & \ddots & \vdots \\
x_{m 1}^{\prime} & x_{m 2}{ }^{\prime} & \cdots & x_{m n^{\prime}}^{\prime}
\end{array}\right]
$$

Among them, $x_{i j}{ }^{\prime}$ stands for the measure value of the $j$-th indicator of the $i$-th year.

In the process of measuring the sustainable development of regional agriculture, in order to eliminate the influence of the original variable sequence with different dimensions and quantity, to ensure the reliability of the measure analysis results, the linear method is used to deal with the initial measure matrix.

$$
\begin{aligned}
& \text { When } x_{i j}^{\prime} \text { is positive entropy flow indicator }: x_{i j}=\frac{x_{i j}{ }^{\prime}-\min _{1 \leq i \leq m} x_{i j}{ }^{\prime}}{\max _{1 \leq i \leq m} x_{i j}{ }^{\prime}-\min _{1 \leq i \leq m} x_{i j}{ }^{\prime}} \\
& \text { When } x_{i j}{ }^{\prime} \text { is negative entropy flow indicator }: x_{i j}=\frac{\max _{1 \leq i \leq m} x_{i j}{ }^{\prime}-x_{i j}{ }^{\prime}}{\max _{1 \leq i \leq m} x_{i j}{ }^{\prime}-\min _{1 \leq i \leq m} x_{i j}{ }^{\prime}}
\end{aligned}
$$

In order to eliminate the influence of the logarithmic calculation of the standardized value, the coordinate of $x_{i j}$ needs to be translated.

$$
y_{i j}=x_{i j}+\theta
$$

In the formula, $\theta$ is the amplitude of the translation. Referring to the reference literature, $\theta>\min \left(x_{i j}\right)$, if the value of $\theta$ closer to $\min \left(x_{i j}\right)$, the measurement of the result is more significant [7]. In this study, the value of $\theta$ is 0.001 , and the transformed matrix $Y=\left[y_{i j}\right]_{m \times n}$ is obtained. 


\subsubsection{Determination of the Entropy Weight of Each Index}

According to the basic principle of information theory, information is the measure of the degree of system order, and entropy is the measure of the degree of system disorder. If the information entropy of the index is smaller, more information is provided by the index, and the higher the weight occupied by the index in comprehensive evaluation. The entropy method is an objective method to determine the index weight by using the numerical structure judgment matrix of the evaluation index. The weight is determined by using the entropy method, and the influence of subjective factors is eliminated as much as possible, so that the evaluation results are more practical.

According to the definition of information entropy, the entropy value $H_{j}$ and entropy weight $\omega_{j}$ of each index are calculated.

$$
\begin{gathered}
H_{j}=-\frac{1}{\operatorname{lnm}} \sum_{i=1}^{m} \frac{y_{i j}}{y_{j}} \ln \frac{y_{i j}}{y_{j}}(j=1,2, \ldots, n) \\
\omega_{j}=\frac{1-H_{j}}{n-\sum_{j=1}^{n} H_{j}}(j=1,2, \ldots, n)
\end{gathered}
$$

In the formula, $y_{j}=\sum_{i=1}^{m} y_{i j}$.

\subsubsection{Calculation of Annual Entropy Information}

The orderly development and evolution of the regional agricultural sustainable development system is reflected by the annual entropy information, and the calculation of the annual entropy information is based on the sequence of one year.

$$
S_{i}=\frac{1}{\ln m} \sum_{j=1}^{n} \frac{y_{i j}}{y_{i}} \ln \frac{y_{i j}}{y_{i}}(i=1,2, \ldots, m)
$$

In the formula, $y_{i}=\sum_{j=1}^{n} y_{i j}$.

\subsubsection{Calculation of the Sustainable Development Score and Coordination Value of System}

The coordinated development of regional agricultural sustainable development system is reflected through the sustainable development score of the system and the coordination value of the system. For the measurement system of the multilayer structure, according to the additive property of the information entropy, the entropy weight $w_{k}$ of each subsystem of the corresponding criterion layer is calculated by using the index entropy weight $\omega_{j}$ of the index layer, and then the entropy weight $w_{j}$ in the corresponding subsystem of each index is obtained. According to the entropy weight $\omega_{j}, w_{j}$ and normalized value $x_{i j}$, the sustainable development score of the main and subsystem ( $D$ and $\left.D_{k}\right)$ is obtained.

$$
\begin{gathered}
w_{k}=\sum_{j=1}^{s} \omega_{j}(k=1,2, \ldots, 5) \\
w_{j}=\frac{\omega_{j}}{w_{k}}(j=1,2, \ldots, n) \\
D=\sum_{j=1}^{n} x_{i j} \omega_{j} \\
D_{k}=\sum_{j=1}^{s} x_{i j} w_{j}(k=1,2, \ldots, 5)
\end{gathered}
$$

In the formula, $k$ is the number of subsystems, while $s$ is the number of the subsystem indicator, and $\mathrm{j}$ is the number of the system indicator.

The coordination value of a system is a quantitative index to describe the coordination development status of each subsystem, indicating the degree of harmony between the elements of the system or the system in the development process, which reflects the trend of the system from disorder to order. Suppose that $\mu$ is the mean value of the sustainable development score of each 
subsystem in the $i$-th year, $\sigma$ is the standard deviation of the score of the sustainable development of each subsystem. Then, the coordination value of system $C_{i}$ is calculated.

$$
C_{i}=1-\frac{\mu}{\sigma}(i=1,2, \ldots, m)
$$

A higher value of the coordination indicates better coordination of each subsystem in a year. Referring to the relevant study $[18,34]$, the value of the coordination is divided into eight levels, as shown in Table 2.

Table 2. The division of coordination level.

\begin{tabular}{ccccccccc}
\hline $\begin{array}{c}\text { Coordination } \\
\text { Value } C_{i}\end{array}$ & $0 \sim 0.09$ & $0.10 \sim 0.29$ & $0.30 \sim 0.39$ & $0.40 \sim 0.49$ & $0.50 \sim 0.59$ & $0.60 \sim 0.69$ & $0.70 \sim 0.89$ \\
\hline $\begin{array}{c}\text { Coordination } \\
\text { Level }\end{array}$ & $\begin{array}{c}\text { Severe } \\
\text { disorder }\end{array}$ & $\begin{array}{c}\text { Moderate } \\
\text { disorder }\end{array}$ & Disorder & $\begin{array}{c}\text { On the verge } \\
\text { of disorder }\end{array}$ & $\begin{array}{c}\text { Barely } \\
\text { coordination }\end{array}$ & $\begin{array}{c}\text { Moderate } \\
\text { coordination }\end{array}$ & $\begin{array}{c}\text { Good } \\
\text { coordination }\end{array}$ & $\begin{array}{c}\text { High quality } \\
\text { coordination }\end{array}$ \\
\hline
\end{tabular}

\section{Case Analysis}

In this study, the data of economic and social are derived from the Sichuan statistical yearbook [29], the data of technology are sourced from the China science and technology statistical yearbook [30], and the data of resources and environmental are mainly from the China environment statistics yearbook [31], some of which are converted from relevant calculation formulas and initial data. The source of initial data is as shown in Table 1. Because the index system not only includes positive entropy flow indicators (such as regional population density), but also contains negative entropy flow indicators (such as gross agricultural product per capita), the indicators need to be standardized to eliminate the dimension influence.

According to the Formulas (1)-(5), the entropy value and entropy weight of each index of the agricultural sustainable development system in Sichuan province are calculated, which lays the foundation for the calculation of the score and coordination value of the sustainable development of the system, as shown in Table 3.

Table 3. The entropy value and entropy weight of each index.

\begin{tabular}{|c|c|c|c|c|c|c|}
\hline \multirow[b]{2}{*}{ Object Layer } & \multicolumn{2}{|c|}{ Rule Layer } & \multicolumn{4}{|c|}{ Indicator Layer } \\
\hline & Index Code & $\begin{array}{c}\text { Entropy } \\
\text { Weight } w_{k}\end{array}$ & Index Code & $\begin{array}{c}\text { Entropy } \\
\text { Value }\end{array}$ & $\begin{array}{c}\text { Entropy } \\
\text { Weight } !_{j}\end{array}$ & $\begin{array}{c}\text { Entropy } \\
\text { Weight } w_{j}\end{array}$ \\
\hline \multirow{25}{*}{$\begin{array}{l}\text { Regional Agricultural } \\
\text { Sustainable } \\
\text { Development System }\end{array}$} & \multirow{5}{*}{$\mathrm{E}$} & \multirow{5}{*}{0.1831} & C11 & 0.8711 & 0.0458 & 0.2500 \\
\hline & & & $\mathrm{C} 12$ & 0.8604 & 0.0496 & 0.2708 \\
\hline & & & C13 & 0.9402 & 0.0212 & 0.1160 \\
\hline & & & C14 & 0.8676 & 0.0470 & 0.2568 \\
\hline & & & C15 & 0.9452 & 0.0195 & 0.1063 \\
\hline & \multirow{5}{*}{$\mathrm{S}$} & \multirow{5}{*}{0.1328} & $\mathrm{C} 21$ & 0.9617 & 0.0136 & 0.1023 \\
\hline & & & $\mathrm{C} 22$ & 0.9139 & 0.0306 & 0.2301 \\
\hline & & & $\mathrm{C} 23$ & 0.9492 & 0.0181 & 0.1360 \\
\hline & & & $\mathrm{C} 24$ & 0.9024 & 0.0347 & 0.2611 \\
\hline & & & C25 & 0.8989 & 0.0359 & 0.2705 \\
\hline & \multirow{5}{*}{$\mathrm{T}$} & \multirow{5}{*}{0.2277} & C31 & 0.9115 & 0.0314 & 0.1381 \\
\hline & & & $\mathrm{C} 32$ & 0.9216 & 0.0278 & 0.1222 \\
\hline & & & $\mathrm{C} 33$ & 0.8936 & 0.0378 & 0.1660 \\
\hline & & & $\mathrm{C} 34$ & 0.8268 & 0.0615 & 0.2702 \\
\hline & & & C35 & 0.8054 & 0.0691 & 0.3036 \\
\hline & \multirow{5}{*}{$\mathrm{R}$} & \multirow{5}{*}{0.2226} & C41 & 0.8070 & 0.0686 & 0.3080 \\
\hline & & & $\mathrm{C} 42$ & 0.9379 & 0.0221 & 0.0991 \\
\hline & & & $\mathrm{C} 43$ & 0.8656 & 0.0477 & 0.2145 \\
\hline & & & $\mathrm{C} 44$ & 0.8854 & 0.0407 & 0.1829 \\
\hline & & & $\mathrm{C} 45$ & 0.8775 & 0.0435 & 0.1955 \\
\hline & \multirow{5}{*}{$\mathrm{E}$} & \multirow{5}{*}{0.2338} & C51 & 0.8610 & 0.0494 & 0.2112 \\
\hline & & & C52 & 0.8292 & 0.0607 & 0.2596 \\
\hline & & & C53 & 0.8904 & 0.0389 & 0.1665 \\
\hline & & & C54 & 0.8926 & 0.0382 & 0.1633 \\
\hline & & & C55 & 0.8688 & 0.0466 & 0.1994 \\
\hline
\end{tabular}


Based on the entropy weights of each layer index in Table 3, the scores and coordination value of agricultural sustainable development in Sichuan Province are calculated by using the Formulas (7)-(10), and the coordination level is divided according to Table 2 . The results are shown in Table 4.

Table 4. The score and coordination value of sustainable development of agriculture in Sichuan.

\begin{tabular}{|c|c|c|c|c|c|c|c|c|}
\hline Year & $\begin{array}{l}\text { Economic } \\
\text { Subsystem }\end{array}$ & $\begin{array}{c}\text { Social } \\
\text { Subsystem }\end{array}$ & $\begin{array}{l}\text { Technical } \\
\text { Subsystem }\end{array}$ & $\begin{array}{l}\text { Resource } \\
\text { Subsystem }\end{array}$ & $\begin{array}{l}\text { Environment } \\
\text { Subsystem }\end{array}$ & $\begin{array}{c}\text { Sustainable } \\
\text { Development Score } D\end{array}$ & $\begin{array}{l}\text { Coordination } \\
\text { Value } C_{i}\end{array}$ & $\begin{array}{c}\text { Coordination } \\
\text { Level }\end{array}$ \\
\hline 2005 & 0.239 & 0.100 & 0.000 & 0.133 & 0.767 & 0.245 & -0.221 & $\begin{array}{c}\text { Severe } \\
\text { disorder }\end{array}$ \\
\hline 2007 & 0.149 & 0.352 & 0.119 & 0.099 & 0.344 & 0.210 & 0.411 & $\begin{array}{l}\text { On the verge } \\
\text { of disorder }\end{array}$ \\
\hline 2009 & 0.386 & 0.635 & 0.312 & 0.186 & 0.167 & 0.326 & 0.439 & $\begin{array}{l}\text { On the verge } \\
\text { of disorder }\end{array}$ \\
\hline 2010 & 0.446 & 0.706 & 0.447 & 0.359 & 0.322 & 0.445 & 0.671 & $\begin{array}{c}\text { Moderate } \\
\text { coordination }\end{array}$ \\
\hline 2013 & 0.756 & 0.699 & 0.718 & 0.610 & 0.337 & 0.614 & 0.729 & $\begin{array}{c}\text { Good } \\
\text { coordination }\end{array}$ \\
\hline 2014 & 0.826 & 0.737 & 0.760 & 0.717 & 0.472 & 0.703 & 0.808 & $\begin{array}{c}\text { Good } \\
\text { coordination }\end{array}$ \\
\hline 2015 & 0.986 & 0.716 & 0.969 & 0.956 & 0.491 & 0.828 & 0.737 & $\begin{array}{c}\text { Good } \\
\text { coordination }\end{array}$ \\
\hline
\end{tabular}

Using the Formulas (1)-(3) and (6), the year information entropy of the agricultural sustainable development in Sichuan province is calculated, as shown in Table 5.

Table 5. Year information entropy of agricultural sustainable development in Sichuan.

\begin{tabular}{ccccccc}
\hline Year & $\begin{array}{c}\text { Economic } \\
\text { Entropy } \\
\text { Change }\end{array}$ & $\begin{array}{c}\text { Social } \\
\text { Entropy } \\
\text { Change }\end{array}$ & $\begin{array}{c}\text { Technological } \\
\text { Entropy } \\
\text { Change }\end{array}$ & $\begin{array}{c}\text { Resource } \\
\text { Entropy } \\
\text { Change }\end{array}$ & $\begin{array}{c}\text { Environment } \\
\text { Entropy } \\
\text { Change }\end{array}$ & $\begin{array}{c}\text { Total } \\
\text { Entropy } \\
\text { Change }\end{array}$ \\
\hline 2005 & -0.240 & -0.088 & -0.019 & -0.203 & -0.356 & -0.906 \\
2006 & -0.048 & -0.349 & -0.174 & -0.059 & -0.437 & -1.067 \\
2007 & -0.204 & -0.354 & -0.177 & -0.181 & -0.306 & -1.223 \\
2008 & -0.241 & -0.345 & -0.214 & -0.177 & -0.274 & -1.251 \\
2009 & -0.276 & -0.371 & -0.252 & -0.196 & -0.173 & -1.269 \\
2010 & -0.255 & -0.343 & -0.267 & -0.228 & -0.195 & -1.288 \\
2011 & -0.289 & -0.328 & -0.262 & -0.255 & -0.145 & -1.279 \\
2012 & -0.299 & -0.303 & -0.248 & -0.276 & -0.171 & -1.297 \\
2013 & -0.307 & -0.290 & -0.284 & -0.268 & -0.160 & -1.309 \\
2014 & -0.296 & -0.266 & -0.279 & -0.276 & -0.196 & -1.313 \\
2015 & -0.305 & -0.229 & -0.298 & -0.276 & -0.185 & -1.292 \\
\hline
\end{tabular}

\section{Result Analysis}

7.1. Analysis of Coordinated Development Situation of Agricultural Sustainable Development System in Sichuan Province

In order to more intuitively observe the changes in the coordinated development of the system, the data of Table 4 are used to generate the coordinated development trend of agricultural sustainable development system, as shown in Figure 5. 


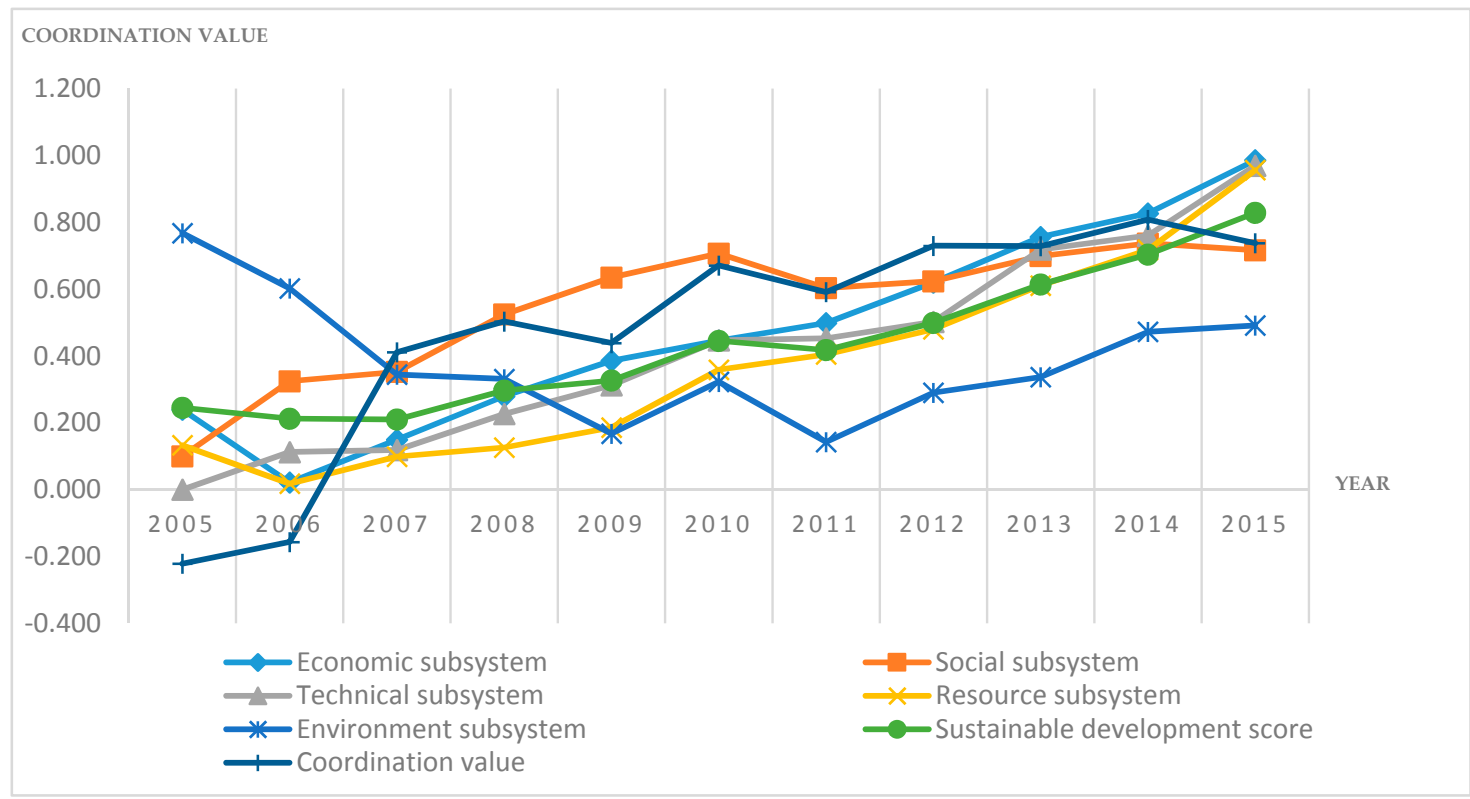

Figure 5. Coordinated development trend of agricultural sustainable development system in Sichuan Province.

\subsubsection{Sustainable Development Situation of the Overall System}

The system of agricultural sustainable development in Sichuan province has been developing in a good and coordinated direction. It can be seen from Table 4 and Figure 5 that the overall sustainable development of agricultural development in Sichuan Province increased rapidly from 2008 to 2015 with an average annual growth rate of $19.56 \%$, and its sustainable development level is generally improving. The agricultural sustainable development in Sichuan province in 2005-2007 was in a backward situation, indicating that the early development of agriculture in Sichuan province failed to coordinate the relationship between economy, society, technology, resources and environment, leading to the low level of sustainable development of agriculture. From 2005 to 2015, the coordinated state of agricultural sustainable development in Sichuan province has experienced changes from serious maladjustment to good coordination. Among them, the coordination degree of agricultural sustainable development is in the slow rising stage from 2005 to 2008, mainly because of the further growth of the agricultural economy, but the rapid population growth (from 66.283 million people in 2005 to 67.044 million people in 2008) and the extensive mode of agricultural economic growth have caused the increase of resource environment pressure, which led to the unstable change of coordinated development in 2008 to 2011. The coordination value of agricultural sustainable development in Sichuan province from 2012 to 2015 is steady between 0.7 and 0.89 , and is in good coordination status. This is mainly due to the government's close attention to environmental protection, the increase of environmental protection investment, the improvement of environmental pressure, coupled with the rapid growth of agricultural economy, so that the agricultural system more coordinated and sustainable.

\subsubsection{Sustainable Development Situation of the Each Subsystem}

(1) The sustainable development level of economic subsystem continues to improve, but the growth of output factors is not significant. The indicators of the economic subsystem have increased with different growth rates between 2005 and 2015. Among them, the growth rate of agricultural fixed assets is the largest, with an average annual growth rate of $30.92 \%$, followed by per capita net income of rural households (13.36\%) and gross agricultural product per capita $(13.21 \%)$, per capita grain production $(0.28 \%)$ and land productivity $(0.01 \%)$ have grown at a slower pace. This shows that Sichuan province has achieved great development in terms of agricultural 
efficiency, farmers' income and promotion of agricultural production development, the overall situation of agricultural economy is running well. However, the growth of agricultural economy mainly depends on the pull of factor input; there are still some problems, such as low input-output ratio of agricultural production, insufficient efficiency of land resources allocation, etc.

(2) The sustainable development level of social subsystem is accelerated but affected by the resistance of population factors. The level of sustainable development of the social subsystem accelerated with an average annual growth rate of 31.08\% from 2005 to 2015, mainly due to the decline in Engel's coefficient of rural residents $(2.93 \%)$ and the increase in the rate of urbanization $(3.75 \%)$, as well as the slow decline in the region's population density $(0.63 \%)$ and the proportion of rural education $(0.99 \%)$. This shows that with the deepening of rural reform, the living standard of farmers and the quality of rural population improved year by year and laid a good foundation for the rural social development. However, the inertia of the population base and population growth (annual natural growth rate of $2.87 \%$ ) slowed the development of the social subsystem to a certain extent.

(3) The sustainability of the technology subsystem increased year by year. From 2005 to 2015, due to the growth rate of different ranges of the number of agricultural scientific research projects, agricultural scientific research input personnel, agricultural research funds and other factors, the average annual growth rate of the sustainable development level of technical subsystem is about $29.57 \%$. This shows that the government has attached importance and support to Sichuan agricultural science and technology innovation in recent years, and made great progress in agricultural science and technology innovation strategy.

(4) The sustainable development level of the resource subsystem is constantly increasing. The average annual growth rate of per capita cultivated land is $0.75 \%$ in 2005-2015, the effective irrigation area has increased from $259.5 \times 10^{4}$ hectares to $273.51 \times 10^{4}$ hectares, the total mechanical power of unit cultivated land area increased from $55.86 \mathrm{kw} / \mathrm{hm}^{2}$ to $110.95 \mathrm{kw} / \mathrm{hm}^{2}$, while per capita electricity consumption in rural has increased from $170.36 \mathrm{kw} \cdot \mathrm{h} /$ person to $276.72 \mathrm{kw} \cdot \mathrm{h} /$ person, and these factors have a positive and favorable impact on the sustainable development of agriculture in Sichuan province. However, the amount of water resources per capita declined with a non-significant rate of $0.83 \%$, which indicates that Sichuan province should attach great importance to the impact of population growth on water resources pressure.

(5) The development of environmental subsystems is extremely unstable, and the change of sustainable development level from 2005 to 2015 presents "W" type characteristics (Figure 4). The level of sustainable development of the environmental subsystem in 2005-2009 is in a downward trend, with a total decline of $78.2 \%$. From 2009 to 2011, there was a brief upward trend, followed by a decline, and from 2011 to 2015, it grew at an average annual rate of 41 per cent. The reason for this phenomenon is that, on the one hand, Sichuan province is located in the southwest of China, where the frequency of natural disasters is high, and there are mainly seasonal drought and flood disasters. Regional natural disasters have been an important factor affecting the safety of the agricultural ecological environment in Sichuan province. On the other hand, in agricultural production, unreasonable use of pesticides, fertilizers, and plastic film also caused the pollution of agricultural ecological environment in Sichuan province. Since 2008, the transfer payment funds of national key ecological function area made by the central government has strengthened the protection and supervision of rural ecological environment at all levels, the financial departments at all levels gradually increased investment in environmental protection; the government's control of rural environmental problems is the key to the steady improvement of the sustainable development level of agricultural environment in Sichuan province after 2011. 


\subsection{Analysis of the Orderly Development Degree and Evolution Trend of Agricultural Sustainable} Development System in Sichuan Province

Based on the dissipative structure theory, the order degree and evolution trend of agricultural sustainable development systems in Sichuan province are judged through the change of entropy. In order to more intuitively observe the orderly development of the system and the evolution of the trend, the data of Table 4 are used to generate the evolution trend chart of agricultural sustainable development system (Figure 6). According to Figure 6, from 2005 to 2015, the economic entropy, social entropy, technology entropy and resource entropy decline smoothly in a whole, which shows that the agricultural subsystem of economy, society, technology and resource in Sichuan province evolved in a healthy and orderly direction. Before 2009, environment entropy continuously increased due to the impact of natural agricultural disasters and unreasonable application of pesticides and fertilizers. This indicates that the function of the agricultural ecological environment is continuously degraded, and the environmental subsystem is evolving in a more disordered direction. However, after 2009, the rate of environmental entropy increase has slowed down, even slightly, reflecting the effectiveness of the government's control of ecological environmental protection after 2008, which is consistent with that mentioned above.

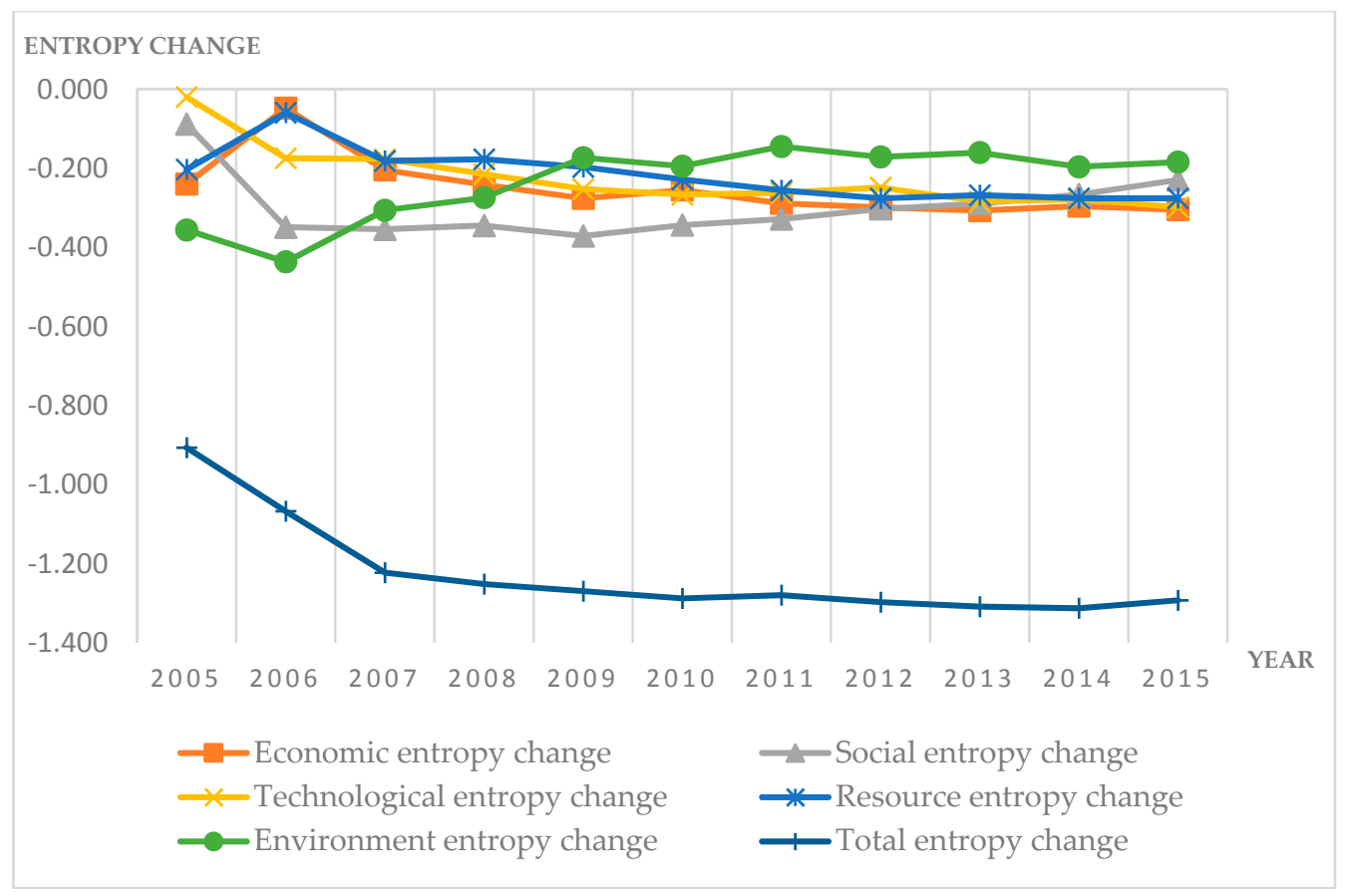

Figure 6. Evolution trend of the agricultural sustainable development system in Sichuan province.

It can be clearly seen from Figure 6 that from 2005 to 2015, the total entropy of the whole system of agricultural sustainable development in Sichuan province declined year by year and began to slow down gradually in 2007. This indicates that the agricultural sustainable development system in Sichuan province has evolved in a healthier and orderly direction, and the whole system tends to be in "dynamic balance".

\section{Conclusions and prospect}

Based on the dissipative structure theory, the index system of the regional agricultural sustainable development system is constructed from the five dimensions of economy, society, technology, resources and environment; the measure model of system is established by using the theory of entropy; 
the agriculture in Sichuan province is selected as an example; and the coordinated development and orderly evolution trend of the system are measured. The conclusions drawn are as follow:

(1) Regional agricultural sustainable development system is a complex system of economy, society, technology, resources and environment. It has the characteristics of dissipative structure, which exist the exchange of material, energy and information with the external environment, and can be benign or malignant evolution. Therefore, the complex evolution of agricultural sustainable development system can be well analyzed through the dissipative structure theory.

(2) The entropy theory has important application value in the evolution analysis of regional agriculture sustainable development system. The change of year information entropy can characterize the orderly development degree and evolution trend of the system. The decrease of entropy means that the order of the system is enhanced, in the state of benign evolution, and the agricultural coordinated development of economy, society, technology, resources and environment is realized. Therefore, entropy can be used as an important quantitative index to explore the evolution of regional agricultural sustainable development system, and the index weight determined by entropy method has a strong objectivity. This is a good reference for the establishment of a new theory and method of regional sustainable development of agriculture.

(3) The situation of the sustainable development of regional agriculture is comprehensively reflected from multi-dimensional perspectives, including economy, society, technology, resources and environment, and provides reference ideas for sustainable development work. When we are dealing with the sustainable development issues of regional agriculture, in addition to the grasp of the overall situation, the dynamic changes of the internal structure should also be analyzed. Aiming at the weak parts of each subsystem, combined with the regional background, well-directed suggestions for future development planning can be put forward.

This study still has some limitations. The core idea of sustainable development is the sustainability, coordination and fairness of the development. This study only focuses on the sustainability and coordination of agricultural sustainable development, for the fairness of sustainable development, there is lack of reference research in the social subsystem, such as the degree of farmers' organization, the gap between urban and rural income distribution, rural social security and so on. In addition, the regional agricultural sustainable development index system is a multi-level, multi-faceted and multi-structure system, but in this paper, by considering the measurability of data, we select the indicators that can measure economic, social, environmental and so on, and research on other factors (such as institutional factors) affecting sustainable development is not enough. These issues need further in-depth analysis and discussion in the future.

Acknowledgments: This research is funded by the National Nature Science Foundation of China (71601134), 2017 Social science "thirteen five" plan annual projects in Sichuan Province (SC17TJ010).

Author Contributions: The study was designed by Canmian Liu in collaboration with all co-authors. Data were collected by Canmian Liu. The first and final drafts were written by Canmian Liu. The drafts were critiqued by Fumin Deng and Xuedong Liang. The results were analyzed by Xuedong Liang and Canmian Liu. The research and key elements of models were reviewed by Fumin Deng. The writing work of corresponding parts and the major revisions of this paper were completed by Canmian Liu.

Conflicts of Interest: The authors declare no conflict of interest.

\section{References}

1. Cui, H.R.; Zhao, L.M.; Xue, Q.L. The Systematic Analysis of Regional Agricultural Sustainable Development Based on the Principles of Dissipative Structure. J. Syst. Dialect. 2005, 13, 60-65.

2. Talukder, B.; Blay-Palmer, A. Elimination Method of Multi-Criteria Decision Analysis (MCDA): A Simple Methodological Approach for Assessing Agricultural Sustainability. Sustainability 2017, 9, 287. [CrossRef]

3. Zhang, X.W.; Ye, Y.X. Three dimensional System Theory of Regional Sustainable Development. J. Harbin Eng. Univ. 2002, 23, 126-129. 
4. Zeng, B.; Hu, Y.C. SD Model Simulation for Sustainable Development of Agriculture in Heilongjiang Province. Chin. Agric. Sci. Bull. 2015, 31, 279-284.

5. Astier, M.; García-Barrios, L.; Galván-Miyoshi, Y.; González-Esquivel, C.E.; Masera, O.R. Assessing the Sustainability of Small Farmer Natural Resource Management Systems. A Critical Analysis of the MESMIS Program. Ecol. Econ. 2012, 17, 25.

6. Pope, J.; Annandale, D.; Morrison-Saunders, A. Conceptualising sustainability assessment. Environ. Impact Assess. Rev. 2004, 24, 595-616. [CrossRef]

7. Yuan, J.H.; Qi, C.J. Dynamic Assessment of Regional Agricultural Sustainability of Hunan Province Based on Entropy Method. Resour. Environ. Yangtze Basin 2013, 22, 152-157.

8. Cao, Z.L. The Construction and Evaluation of Regional Agricultural Sustainable Development Index System-A Case Study of Hengyang City. Econ. Geogr. 2012, 32, 113-116.

9. Gomez-Limon, J.A.; Sanchez-Fernandez, G. Empirical evaluation of agricultural sustainability using composite indicators. Ecol. Econ. 2010, 69, 1062-1075. [CrossRef]

10. Baumgartner, R.J.; Zielowski, C. Analyzing zero emission strategies regarding impact on organizational culture and contribution to sustainable development. J. Clean. Prod. 2007, 15, 1321-1327. [CrossRef]

11. Rasul, G.; Thapa, G.B. Sustainability of ecological and conventional agricultural systems in Bangladesh: An assessment based on environmental, economic and social perspectives. Agric. Syst. 2004, 79, 327-351. [CrossRef]

12. Gustavson, K.R.; Lonergan, S.C.; Ruitenbeek, H.J. Selection and modeling of sustainable development indicators: A case study of the Fraser River Basin, British Columbia. Ecol. Econ. 1999, 28, 117-132. [CrossRef]

13. Stevenson, M.; Lee, H. Indicators of sustainability as a tool in agricultural development: Partitioning scientific and Participatory Processes. Int. J. Sustain. Dev. World Ecol. 2001, 8, 57-65. [CrossRef]

14. Food and Agriculture Organization (FAO). Sustainability Assessment of Food and Agriculture Systems (SAFA) Guidelines; Natural Resources Management and Environment Department: Rome, Italy, 2012.

15. Walters, J.P.; Archer, D.W. Exploring agricultural production systems and their fundamental components with system dynamics modelling. Ecol. Model. 2016, 33, 51-65. [CrossRef]

16. Ulgiati, S.; Odum, H.T.; Bastianoni, S. Emergy use, environmental loading and sustainability: An emergy analysis of Italy. Ecol. Model. 1994, 73, 215-268. [CrossRef]

17. Ghiellini, P.; Zucaro, A.; Viglia, S.; lgiati, S. Monitoring and evaluating the sustainability of Italian agricultural system. An emergy decomposition analysis. Ecol. Model. 2014, 271, 132-148. [CrossRef]

18. Li, C.; Li, W.F.; Li, L.R. Assessment of regional agro-ecosystem sustainable development based on grey correlation and models. Ecol. Sci. 2014, 33, 373-378.

19. Cahya, D.L. Analysis of Urban Agriculture Sustainability in Metropolitan Jakarta (Case Study: Urban Agriculture in Duri Kosambi). Proced. Soc. Behav. Sci. 2016, 227, 95-100. [CrossRef]

20. Dong, F.X.; Mitchell, P.D.; Colquhoun, J. Measuring farm sustainability using data envelope analysis with principal components: The case of Wisconsin cranberry. J. Environ. Manag. 2015, 147, 175-183. [CrossRef] [PubMed]

21. Lu, B.; Han, W. Sustainable Development Level in Rural China Based on Osculating Value Method. Asian Agric. Res. 2009, 1, 1-4.

22. Vlontzos, G.; Niavis, S.; Nanos, B. A DEA approach for estimating the agricultural energy and environmental efficiency of EU countries. Renew. Sustain. Energy Rev. 2014, 9, 91-96. [CrossRef]

23. Chen, L.; Zhou, J.X.; Li, X.M. Evaluation of Urban Ecological Level Based on Dissipative Structure TheoryA Case Study in Wu Han. Res. Environ. Yangtze Basin 2007, 16, 786-790.

24. Chen, L.; Tian, S.Q.; Zhang, K.; Chen, W.K. Analysis on the Ecological Security Measure of Cultivated Land in Sichuan Province Based on the Dissipative Structure Theory. Res. Soil Water Conserv. 2017, 24, 307-313.

25. Hua, J.; Li, Z.L.; Huang, D.C. An international river water resource development cooperation system based on dissipative structure theory. Res. Sci. 2016, 38, 239-247.

26. Li, H.; Dai, W.T. Analysis of transformation development of resource-based city based on dissipative structure theory: A case study of Xuzhou city. China Min. Mag. 2017, 26, 27-32.

27. Shi, W.F. Entropy Analysis of the Coupled Human-Earth System: Implications for Sustainable Development. Sustainability 2017, 9, 1264. [CrossRef]

28. Roth, G.S. Are free radicals causes or effects of aging? The entropy theory. Aging Clin. Exp. Res. 1993, 5, 241-242. [CrossRef] 
29. Sichuan Bureau of Statistics. Sichuan Statistical Yearbook; China Statistics Press: Beijing, China, $2006-2016$. Available online: http:/ / www.sc.stats.gov.cn/tjcbw/tjnj/ (accessed on 6 November 2017).

30. State Statistics Bureau. China Statistical Yearbook on Science and Technology; China Statistics Press: Beijing, China, 2006-2016.

31. State Statistics Bureau. China Statistical Yearbook on Environment; China Statistics Press: Beijing, China, 2006-2016.

32. Wang, J.; Xie, S.Y.; Ren, W.; Dai, G.F. Comprehensive Evaluation of Ecological Agriculture Sustainability in Three Gorges area. J. Southwest Norm. Univ 2011, 36, 86-91.

33. Zhao, Z.G.; Wang, K.R.; Xie, X.L. Eco-Safety Assessment of Agricultural Sustainable Development in Jiangxi Province. J. Ecol. Rural Environ. 2012, 28, 225-230.

34. Chen, J.; Zeng, Z.X. Research on the Appraise Model of Coordination Development among Society, Economy, Resource and Environment. Sci. Manag. Res. 2004, 22, 9-12.

(C) 2017 by the authors. Licensee MDPI, Basel, Switzerland. This article is an open access article distributed under the terms and conditions of the Creative Commons Attribution (CC BY) license (http://creativecommons.org/licenses/by/4.0/). 